\title{
GERAKAN LITERASI ISLAMIYAH MELALUI PROGRAM DAKWAH DAN TARBIYAH DI DESA MANGELORENG KABUPATEN MAROS
}

\author{
Istikhariyah Muin \\ istikhariyahmuin@stiba.ac.id

\section{Amirullah} \\ STKIP Muhammadiyah Barru \\ amirsibali14@gmail.com
}

Sekolah Tinggi Ilmu Islam dan Bahasa Arab (STIBA) Makassar

\section{Keywords : \\ Da'wah and Tarbiyah, Baruga Village, KKN STIBA, Maros.}

\begin{abstract}
$A B S T R A C T$
Among the forms of community service of STIBA Makassar KKN students in Baruga Village, Bantimurung District, Maros Regency is to conduct the Da'wah and Tarbiyah programs. This program aimed to increase the comprehension and competence of Islamic communities in Baruga Village. The details of the Da'wah and Tarbiyah programs are: 1) Dirosa activities; 2) Tahsin activities; 3) Teaching for Muslim women; 4) Quranic Advice; 5) Teaching PAI; 6) Teaching of TKA/TPA; 7) Training for funeral ritual. The output of the da'wah and tarbiyah programs made a positive contribution to increasing the Islamic understanding of residents in Baruga Village.
\end{abstract}

\section{Kata kunci :}

\section{ABSTRAK}

Dakwah dan Tarbiyah, Desa Baruga, KKN STIBA, Maros.

Salah satu bentuk pengabdian masyarakat mahasiswa KKN STIBA
Makassar di Desa Baruga, Kecamatan Bantimurung, Kabupaten
Maros adalah melaksanakan program Dakwah dan Tarbiyah.
Tujuan program ini adalah untuk meningkatakan pemahaman dan
kompetensi keislaman masyarakat di Desa Baruga. Adapun rincian
program Dakwah dan Tarbiyah adalah: 1) Kegiatan Dirosa; 2)
kegiatan Tahsin; 3) Taklim Muslimah; 4) Tausiyah Qur'aniyah; 5)
Mengajar PAI; 6) Pembinaan TKA/TPA; 7) Pelatihan
Penyelenggaraan Jenazah. Luaran program dakwah dan tarbiyah
memberikan kontribusi positif dalam meningkatkan pemahaman
keislaman warga di Desa Baruga.




\section{PENDAHULUAN}

\section{Gambaran Umum Desa Mangeloreng}

Desa Mangeloreng merupakan salah satu desa di kecamatan Bantimurung kabupaten Maros, Sulawesi Selatan dengan desa-desa dan kelurahan lain disekitarnya. Sebelah utara desa Tukamasea, sebelah selatan desa Minasabaji, sebelah barat desa Mattoanging dan sebelah timur kel. Kalabbireng. Desa ini memiliki luas 1.072,0900 Ha.

Sebagian besar penduduk desa Mangeloreng berprofesi sebagai petani, peternak dan pedagang. Hal itu sesuai dengan keadaan alam yang wilayahnya terdapat banyak sawah. Jumlah warga yang ada di desa Mangeloreng ini ada sekitar 3.330 jiwa yang terbagi atas empat dusun yaitu dusun Kaluku, Lopi-Lopi, Mangngai dan Bontopadalle.

Sedikit gambaran bahwa desa Mangeloreng dulunya adalah desa yang bersatu dengan desa Minasabaji. Namun, seiring dengan berjalannya dan berkembangnnya zaman serta bartambahnya masyarakat akhirnya desa tersebut dipisah dan berdiri sendiri. Pada KKN I STIBA Makassar, jumlah penduduk desa Mangeloreng sekitar 3.014 jiwa. Pada KKN II STIBA Makassar, jumlah penduduk desa Mangeloreng sekitar 3.194 jiwa. Pada KKN III STIBA Makassar, jumlah penduduk desa Mangeloreng sekitar 3.330 jiwa.

Desa Mangeloreng mengalami perubahan yang pesat, kini administrasi dan kelembagaan di desa tersebut terus melakukan perbaikan, desa Mangeloreng memiliki empat dusun diantaranya dusun Kaluku, Lopi-Lopi, Mangngai, dan Bontopadalle. Jumlah warga yang ada di desa Mangeloreng ini ada sekitar 3.330 jiwa.

\section{Pemerintahan Desa}

Bagian struktur organisasi pemerintahan desa terdiri atas Kepala Desa, Bapak Muhammad Darwis, SE, Sekretaris Desa, Kepala Urusan Umum dan Perencanaan Nurbayanti, Kepala Urusan Keuangan Mas'ud Prakasih, Seksi Pemerintahan Bapak Sirajuddin, Seksi Kesejahteraan dan Pelayanan Bapak Andi Muswarrang, Kepala dusun Mangngai Bapak Ambo Lai, dusun Kaluku Bapak Muhammad Arifuddin, dusun LopiLopi Bapak H. Jaunaid Dg. Mattorang, dusun Bontopadalle Bapak Muh. Abbas.

\section{Letak Georafis}

Desa Mangeloreng secara administratif berada dalam wilayah pemerintahan kecamatan Bantimurung dengan luas wilayah desa $8,72 \mathrm{~km}^{2}$ dan luas hutan $150 \mathrm{~km}^{2}$ yang terletak disebelah timur ibu kota kabupaten Maros dengan jarak $10 \mathrm{Km}$. Desa Mangeloreng termasuk wilyah dataran rendah, berbukit atau sampai dengan elevasi 0 sampai 50 meter dari Permukaan Laut.

\section{Keadaan Tanah Dan Iklim}

Desa Mangeloreng secara umum adalah lahan sawah tadah hujan yang mempunyai potensi untuk pengembangan berbagai jenis tanaman padi, palawija dan tanaman holtikultura, ternak kecil maupun ternak besar dan pemeliharaan ikan air tawar. 
WAHATUL MUJTAMA': Jurnal Pengabdian Masyarakat

Vol. 1, No. 2 (2020) : Hal. 200-208

Website: https://journal.stiba.ac.id

Jenis tanah di wilayah kerja desa Mangeloreng termasuk jenis tanah mediteran dan alovial dengan PH 5,5- 7 dan lahan sawah 5-6. Berdasarkan pada curah hujan di desa Mangeloreng, umumnya curah hujan tertinggi pada bulan Desember dan Januari dan curah hujan terendah pada bulan Agustus dan September (sumber program BPP Bantimurung). Menurut pembagian tipe iklim tergolong dalam kategori beriklim tropis tipe C2 dimana bulan basah 7-9 bulan dan bulan kering 2-3 bulan dengan temperature 20$30^{\circ} \mathrm{C}$

\section{PEMBAHASAN}

\section{Kegiatan DIROSA (Pendidikan Orang Dewasa)}

DIROSA (Pendidikan Orang Dewasa) adalah pola pembinaan Islam bagi kaum muslimin yang lebih difokuskan pada pemula seperti ibu-ibu, bapak-bapak, remaja, anakanak maupun muallaf yang dikelola secara sistematis, dan berlangsung terus menerus. DIROSA sangat membantu kaum muslimin yang belum bisa membaca al-Quran maupun yang masih terbata-bata dalam penyebutan huruf hijaiyyah. ${ }^{1}$ DIROSA selain mudah dipelajari bukunyapun singkat, padat dan jelas. Cara mempelajarinya akan dipandu langsung oleh orang-orang yang telah mahir dalam penyebutan huruf hijaiyyah dan telah melalui pelatihan-pelatihan DIROSA.

Pelaksanaan kegiatan DIROSA di Desa Mangeloreng dilakukan di masjid di setiap dusun di desa Mangeloreng yang dilaksanakan sesuai kesepakatan mudarrisah dengan darisahnya. Adapun metode yang digunakan sesuai dengan metode yang telah ditentukan di dalam buku DIROSA. Kegiatan DIROSA sangat mendapat respons positif dari masyarakat di Desa Mangeloreng karena sebelumnya mereka telah belajar DIROSA dari KKN STIBA Makassar sebelum angkatan ke-III, selain telah mengenal DIROSA, masyarakat di desa Mangeloreng juga merupakan masyarakat yang aktif mengikuti pengajian di setiap dusun di desa Mangeloreng.

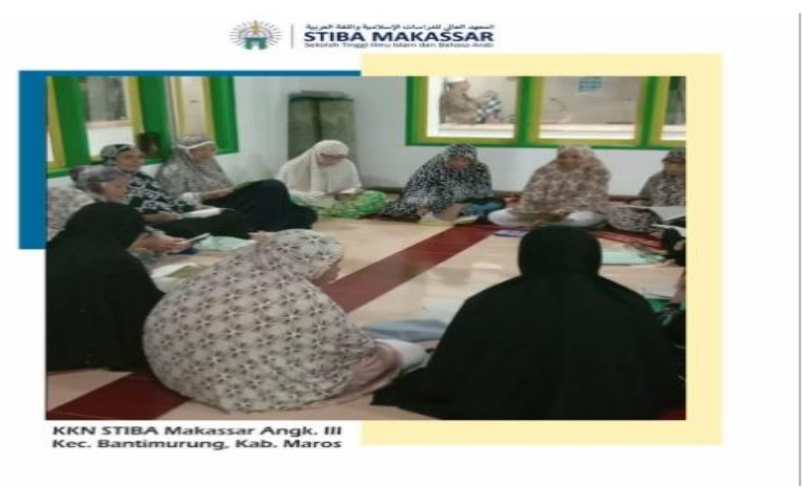

Gambar 1. Pelaksanaan Dirosa

\footnotetext{
${ }^{1}$ Wijaya, H. (2020). Pembelajaran Metode Dirosa di Desa Majannang Kabupaten Gowa. WAHATUL MUJTAMA': Jurnal Pengabdian Masyarakat, 1(1), 67-74. Hal. 70
} 
WAHATUL MUJTAMA': Jurnal Pengabdian Masyarakat

Vol. 1, No. 2 (2020) : Hal. 200-208

Website: https://journal.stiba.ac.id

\section{Kegiatan Tahsin ( Perbaikan Bacaan al-Quran)}

Tahsin (Perbaikan Bacaan al-Quran) adalah pola pembinaan Islam bagi kaum muslimin yang lebih difokuskan pada perbaikan makharaj huruf hijaiyyah yang dikelola secara sistematis, dan berlangsung terus menerus. Tahsin sangat membantu kaum muslimin yang telah mahir membaca al-Quran namun belum tepat makharajnya. tahsin selain mudah dipelajari bukunyapun singkat, padat dan jelas. Cara mempelajarinya akan dipandu langsung oleh orang-orang yang telah mahir dalam penyebutan huruf hijaiyyah dan telah melalui pelatihan-pelatihan mudarrisah tahsin dan telah lulus tasfiyah.

Pelaksanaan kegiatan tahsin di desa Mangeloreng dlaksanakan di posko KKN, Masjid Babussalam BTP, masjid Nurul Karim Lopi-Lopi dan Masjid al-Musafir So'dang dan dilaksanakan sesuai kesepakatan mudarrisah dengan darisahnya. Adapun metode yang digunakan sesuai dengan metode yang telah ditentukan di dalam buku tahsin. Kegiatan tahsin sangat mendapat respons positif dari masyarakat di desa Mangeloreng utamanya anak SMA dan SMP karena sebelumnya mereka telah belajar tahsin dari TK/TPA selain telah mengenal tahsin masyarakat di desa Mangeloreng merupakan masyarakat yang aktif mengikuti pengajian di setiap dusun di desa Mangeloreng.

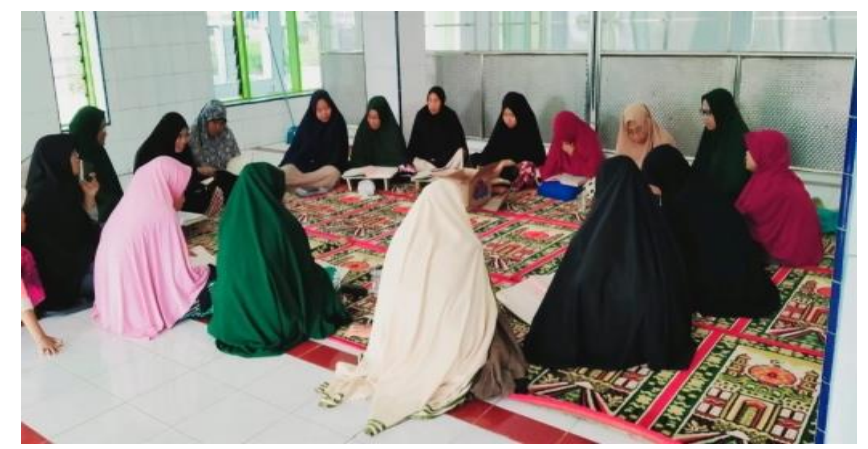

Gambar 2. Perbaikan bacaan Al Qur'an (Tahsin)

\section{Ta'lim Muslimah}

Kegiatan Ta'lim Muslimah adalah majelis ta'lim khusus muslimah yang berisi matei-materi tazkiyatun nafs (pensucian jiwa) dan pembahasan seputar fikih ibadah, fikih wanita dan pembahasan fikih lainya. Kegiatan ini sangat penting untuk masyarakat terutama bagi ibu-ibu yang belum pernah mempelajari ilmu Islam, karena kegiatan ini menjadi wadah bagi muslimah untuk menimba ilmu, sharing barbagi masalah dan memberi solusi. Kegiatan ini dilaksanakan di enam masjid di Desa Mangeloreng pada waktu yang berbeda-beda, sesuai dengan undangan yang telah disebarkan, dan kegiatan ini terlaksana sekali sepekan selama KKN.

Kegiatan ini mendapat respons yang sangat baik bagi masyarakat di desa mangeloreng teruatama bagi ibu-ibu, karena selain menjadi wadah untuk menimba ilmu, Ta'lim Muslimah juga menjadi ajang silaturahmi bagi ibu-ibu setempat. 


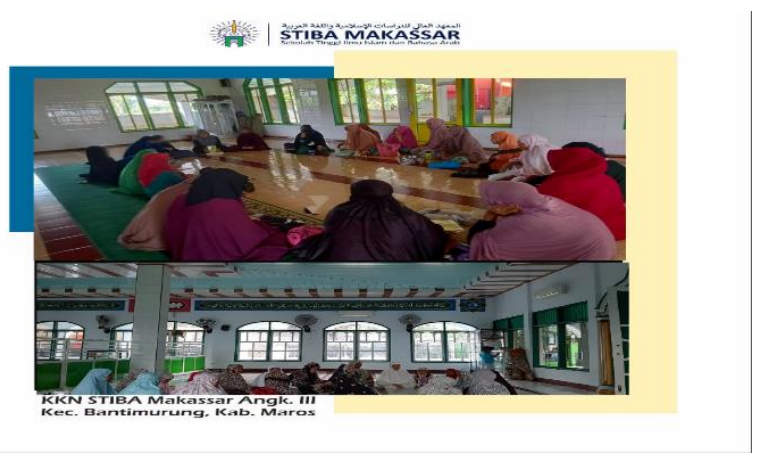

\section{Taushiyah Quraniyah}

Tausiyah Quraniyah adalah salah satu progam kerja mahasiswi KKN angkatan III tahun 2020 STIBA Makassar, untuk seluruh lapisan masyarakat khususnya ibu-ibu di desa Mangeloreng. Kegiatan Tausiyah Quraniyah dilaksanakan pada tanggal 12 Februari 2020 yang dirangkaikan pula dengan kegiatan Ramah Tamah Muslimah SeMangeloreng dan Bakti Sosial. Kegiatan ini diselenggarakan di masjid Al Musafir So'dang Kaluku. Kegiatan ini dihadiri oleh kurang lebih 89 peserta, yang terdiri ibu-ibu dan remaja masjid dari setiap dusun di desa Mangeloreng.

Adapun tujuan dari program kerja Tausiyah Quraniyah ini yaitu: 1) sebagai media untuk memperkokoh silaturahmi antar dusun dalam upaya memperkuat persaudaraan masyarakat yang dilandasi oleh ukhuwah Islamiyah; 2) menumbuhkan rasa cinta masyarakat terhadap alquran serta pemahaman pentingnya penerapan nilai-nilai alquran dalam kehidupan; 3) sebagai sarana untuk menumbuhkan semangat dalam menghadiri majelis ilmu.

Al-Qur'an diturunkan untuk mengubah pikiran manusia, kecenderungannya, dan tingkah lakunya, memberi petunjuk kepada mereka, mengubah kesesatan dan kebodohan mereka, mengarahkan mereka kepada suatu hal yang baik untuknya, dan membekali mereka dengan pikiran-pikiran baru tentang tabiat manusia dan misinya dalam kehidupan, nilai-nilai, dan moral. ${ }^{2}$ Dalam waktu yang relatif singkat, al-Qur'an telah berhasil membentuk kepribadian manusia yang utuh, seimbang, damai dan tenteram. ${ }^{3}$

\footnotetext{
${ }^{2}$ Najati, M. U., \& Mohammad, A. (2004). Al-Quran dan ilmu jiwa.

${ }^{3}$ Mar'ati, R., \& Chaer, M. T. (2017). Pengaruh pembacaan dan pemaknaan ayat-ayat al-qur'an terhadap penurunan kecemasan pada santriwati. Psikohumaniora: Jurnal Penelitian Psikologi, 1(1), 30-48.
} 


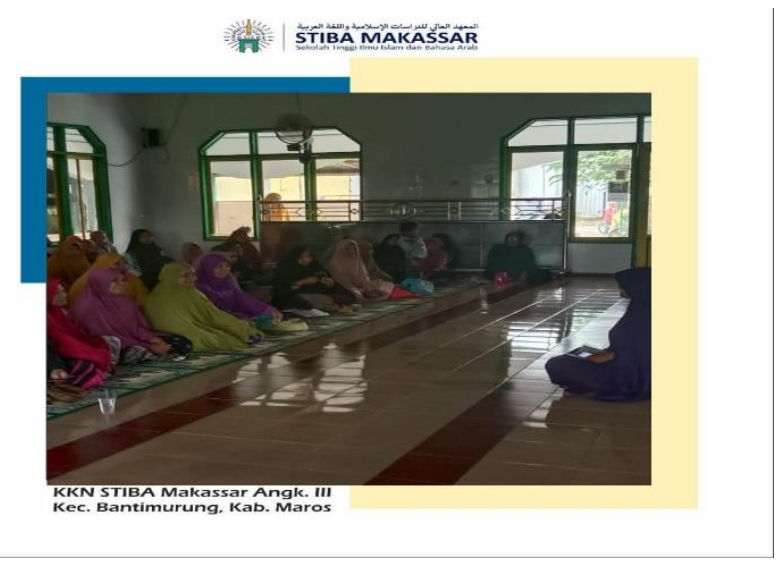

\section{Mengajar Pendidikan Agama Islam}

Kegiatan mengajar pendidikan Islam merupakan program kerja mahasiswi KKN III STIBA Makassar dengan memberikan pemahaman dan wawasan keIslaman serta tambahan kosa kata bahasa Arab kepada siswa/i di sekolah TKN 14 Pembina (Dusun kaluku) dan UPTD SDN 173 Inpres Mangngai (Dusun Mangngai) yang terletak di Desa Mangeloreng, yang dilaksanakan pada waktu-waktu yang sudah disepakati antara mahasiswi dengan guru yang bersangkutan. Selain berfungsi sebagai alat komunikasi pada umumnya pengajaran bahasa Arab pada tingkatan ini fungsinya adalah sebagai bahasa agama dan ilmu pengetahuan. Oleh karenanya, mata pelajaran bahasa Arab pada tingkat MI/SD tidak terpisahkan dengan mata pelajaran Pendidikan Agama. ${ }^{4}$ Adapun tujuan pengajaran bahasa Arab di Madrasah Ibtidaiyah adalah agar siswa dapat melakukan komunikasi sederhana dalam bahasa Arab dan dapat memahami bacaanbacaan sederhana dalam suatu wacana. ${ }^{5}$

Metode pengajaran dalam pendidikan agama Islam perlu mencakup pembinaan psikomotor, kognitif, afektif dan ketrampilan. Namun dalam bagian afektif inilah yang paling rumit dan sering dikeluhkan oleh para pendidik khususnya materi agama, karena menyangkut pembinaan rasa aman, dan rasa beragama. Agar kita dapat mengetahui :metode-metode yang cocok digunakan untuk menyampaikan materi terutama materi dalam pengajaran pendidikan agama Islam agar lebih luwes dalam menyampaikan materi ajarnya. Dan untuk anak didik agar mudah memahami materi yang diajarkan oleh pendidiknya. ${ }^{6}$

\footnotetext{
${ }^{4}$ Syaifullah, M. (2016). Pembelajaran Kooperatif Tipe Make A Match Dalam Meningkatkan Penguasaan Kosa Kata Bahasa Arab Santri TPA Al-Barokah Hadimulyo Timur Metro Pusat. At-Ta'dib, 11(2), 305321. Hal 310

${ }^{5}$ Hidayati, N., \& Ridwan, N. A. (2005). Strategi Pembelajaran Bahasa Arab Untuk Anak. Skripsi, Malang: Jurusan Sastra Arab Fakultas Sastra Universitas Negeri Malang. Hal 15-16

${ }^{6}$ Sarbani, D. A., \& Alfatih, M. P. I. (2015). Metode Pengajaran dalam Pendidikan Agama Islam. Jurnal Al Fatih. Hal 45
} 


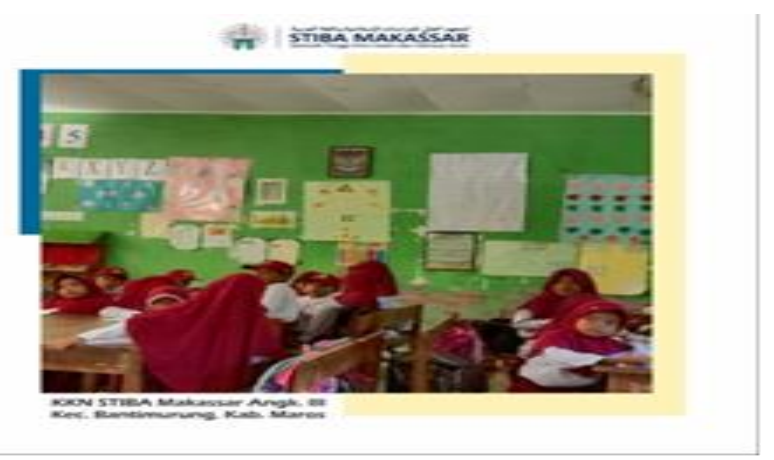

\section{Pembinaan TK/TPA}

Kegiatan pembinaan TK/TPA merupakan sebuah kegiatan keagamaan yang berupaya sebagai sarana memperkenalkan tata cara membaca Alquran dan juga merupakan kegiatan rutin mahasiswi KKN III STIBA Makassar, TPA atau kepanjangan dari Taman Pendidikan Alquran yang diperankan oleh anak-anak, karena pada usia dini anak-anak masih dalam tahap kognitif. Selain itu, Alquran merupakan kitab suci serta panduan hidup bagi seorang muslim yang wajib dipelajari oleh semua umat Islam.

Pelaksanaan kegiatan TK/TPA di Desa Mangeloreng bertempat di empat lokasi, yang terdapat di dusun yang berbeda, terdapat satu TK/TPA yang sudah ada sebelummya yakni (TKQ/TPQ Nurul Jannah) yang terletak di dusun Kaluku, serta satu TPQ yang dirintis oleh Tim KKN III STIBA Makassar (TPQ Nurul Karim) di dusun Lopi-Lopi dan dua TPA yang belum diresmikan oleh pemerintah setempat yang berada di dusun Mangngai dan Bontopadalle. Kegiatan TK/TPA yang ini dibimbing langsung oleh mahasiswa/i KKN dan pembina masing-masing TK/TPA, dalam perencanaanya kegiatan TK/TPA dilaksanakan setiap jadwal masuk TPA di lingkungan dusun setempat.

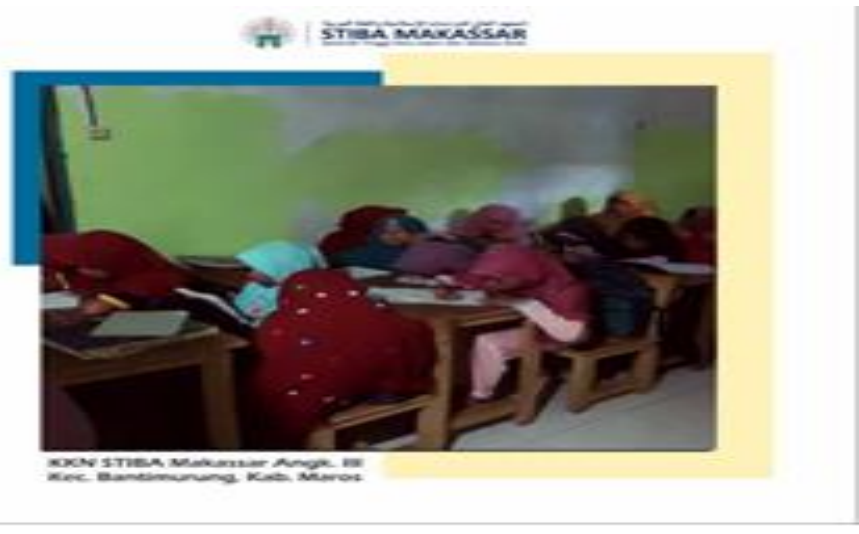

Kegiatan TK/TPA yang dilakukan meliputi pembimbingan anak dalam membaca Iqra' dan Alquran. Dalam pembimbingan belajar membaca, anak-anak diajari satu persatu dengan saling bergantian sehingga anak-anak yang lain masih menunggu dan seperti kebiasaan anak kecil pada umumnya di sela-sela menunggu gilirannya, anak-anak saling bermain dengan teman-temannya. Anak-anak sangat antusias dalam mengikuti kegiatan 
WAHATUL MUJTAMA': Jurnal Pengabdian Masyarakat

Vol. 1, No. 2 (2020) : Hal. 200-208

Website: https://journal.stiba.ac.id

TK/TPA ini. Selain proses pembelajaran pembimbingan bacaan Iqra' dan Alquran, santri juga diajarkan dan dilatih untuk menghafal do'a-do'a harian, surah-surah pendek, adabadab serta beberapa kosa kata bahasa Arab.

\section{Pelatihan Penyelenggaraan Jenazah}

Pelatihan Penyelenggaraan Jenazah merupakan suatu pelatihan untuk meningkatkan pengetahuan masyarakat Mangeloreng dalam hal tata cara memandikan dan mengkafani jenazah sebagaimana yang dicontohkan oleh Rasulullah saw. Kondisi masyarakat dewasa ini sedikit sekali orang yang bisa menyelenggarakan jenazah karena kurangnya pengetahuan, keterampilan, dan keberanian masyarakat tentang hal itu. Padahal pengurusan jenazah lebih afdhal jika dilaksanakan oleh keluarga dekat. Pegurusan jenazah di dalam Islam hukumnya fardhu kifayah, dan mempelajari ilmu tentang peraturan-peraturan di sekitar penyelengaraan jenazah itupun merupakan fardhu kifayah, artinya berdosalah seluruh anggota suatu kelompok kaum muslimin apabila dalam kelompok tersebut tidak terdapat orang yang berilmu cukup untuk pengurusan jenazah; tetapi setelah ada beberapa orang yang mampu menyelenggarakannya, maka terbebaslah semua masyarakat tersebut dari dosa. ${ }^{7}$

Pelaksanaan kegiatan pelatihan penyelenggaraan jenazah di desa Mangeloreng dilaksanakan dua kali, di Masjid Nurul Iman Dusun Mangngai dan di Masjid Babussalam Dusun Bonto Padalle. Kegiatan pelatihan penyelenggaraan jenazah sangat mendapat respons positif dengan baik dari masyarakat Mangeloreng karena sebelumnya mereka belum memahami tata cara pelaksanaan penyelenggaraan jenazah yang sesuai dengan syariat Islam (Budisiwi, 2013 hal. 3).

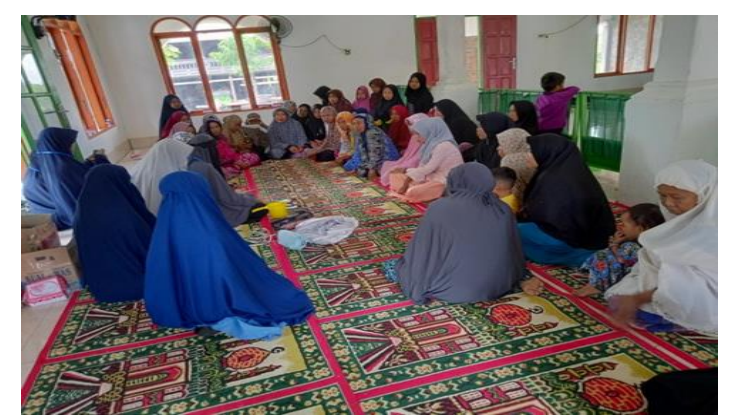

\section{KESIMPULAN}

Gerakan literasi Islamiyah melalui program dakwah dan tarbiyah di Desa Mangeloreng Kabupaten Maros bertujuan untuk meningkatkan kualitas pemahaman agama Islam masyarakat Desa Mangeloreng, Kecamatan Bantimurung, Kabupaten

\footnotetext{
${ }^{7}$ Darmawangsa, A., \& Abdullah, N. (2020). Training of Trainer Penyelenggaraan Jenazah Bagi Tokoh Masyarakat. Al-Tafaqquh: Journal of Islamic Law, 1(1), 90-94. Hal 91
} 
Maros. Kegiatan ini merupakan bentuk pengabdian masyarakat oleh mahasiswi STIBA Makassar dan diharapkan berkontribusi positif terhadap peningkatan kualitas pengetahuan dan pemahaman keislaman masyarakat secara baik dan benar, khususnya bagi kalangan muslimah di Desa Mangeloreng. Melalui gerakan literasi islamiyah melalui program dakwah dan tarbiyah di Desa Mangeloreng Kabupaten Maros, disimpulkan bahwa sebagian muslimah di Desa Mangeloreng sebelum mengikuti berbagai program literasi islamiyah memiliki pengetahuan dan pemahaman keislaman yang minim dan setelah mengikuti kegiatan literasi islamiyah muslimah di Desa Mangeloreng muslimah memiliki peningkatan dalam hal pengetahuan dan pemahaman keislaman.

\section{DAFTAR PUSTAKA}

Darmawangsa, A., \& Abdullah, N. (2020). Training of Trainer Penyelenggaraan Jenazah Bagi Tokoh Masyarakat. Al-Tafaqquh: Journal of Islamic Law, 1(1), 90-94.

Hidayati, N., \& Ridwan, N. A. (2005). Strategi Pembelajaran Bahasa Arab Untuk Anak. Skripsi, Malang: Jurusan Sastra Arab Fakultas Sastra Universitas Negeri Malang.

Najati, M. U., \& Mohammad, A. (2004). Al-Quran dan ilmu jiwa. Mar'ati, R., \& Chaer, M. T. (2017). Pengaruh pembacaan dan pemaknaan ayat-ayat al-qur'an terhadap penurunan kecemasan pada santriwati. Psikohumaniora: Jurnal Penelitian Psikologi, $1(1), 30-48$.

Syaifullah, M. (2016). Pembelajaran Kooperatif Tipe Make A Match Dalam Meningkatkan Penguasaan Kosa Kata Bahasa Arab Santri TPA Al-Barokah Hadimulyo Timur Metro Pusat. At-Ta'dib, 11(2), 305-321.

Sarbani, D. A., \& Alfatih, M. P. I. (2015). Metode Pengajaran dalam Pendidikan Agama Islam. Jurnal Al Fatih.

Tajuddin Abdul Wahhab bin Taqiyuddin al-Subki, Al-Asybah wa al-Nazhair, Jilid I (Cet. I; Beirut: Dar al-Kutub al-Ilmiyah, 1411 H/ 1991 M), h. 41.

Wijaya, H. (2020). Pembelajaran Metode Dirosa di Desa Majannang Kabupaten Gowa. WAHATUL MUJTAMA': Jurnal Pengabdian Masyarakat, 1(1), 67-74. 